\title{
Assessement of the Ability of Elective Choice System
}

Artyom Bologov

Freelancer; artyom.bologov@gmail.com

Abstract

I am studying in the greenfield liberal arts school, meaning there are a lot of experiments and hot patching that happens during the studying process. While some things change, one thing got through three years of school existence almost unchanged - the elective choice system. And now, when this system is finally questioned as to the one that can allow students' self-interest to lead to a constructive and just distribution to electives, I want to assess the ability of current elective choice system - the semester-rating based one, with the seven-median grading - to distribute students satisfiable in a different modelled situation and to find out if this system is that stable in critical conditions. What I suppose is that this system will be stable enough in a short-term perspective, but will need to be changed after some time.

Keywords: game theory-based models; agent based models; elective choice system

JEL Classification: 129, Z13

(c) Artyom Bologov, 2020

I 'll use two models - the Game Theory-based one and agent-based, to look into how the elective course choice is made and where this process may destabilize. Because both of these ways can have their insights and shortcoming, they will complement each other and can lead to a reasonable model of the elective choice process.

\section{Game-theoretic Model}

To simplify the problem, let's imagine the elective course choice as the $2 \times 2$ game: two studentplayers are interested in having comfortable learning process that is as close to their interests as possible; there are also two elective courses that students can choose, but if both students choose one elective, it will become overcrowded, and both of students will be unable to learn. That's the most simple coordination problem that we can see - there's not enough place for everyone on every course. Such a problem-game can be expressed as a table, similar for both students:

\begin{tabular}{ccc}
\hline & Course 1 & Course 2 \\
\hline Course 1 & 0 & 1 \\
Course 2 & 1 & 0 \\
\hline
\end{tabular}

\section{Choice-function}

In the most primitive form, the motivation of the student $k$ to go to the elective course $\epsilon_{i}$ can be expressed as:

$$
\mu_{k i}=\beta-\left(\pi_{k}-\epsilon_{i}\right)^{2},
$$

where $\mu_{i}$ is the motivation to go to the elective $\epsilon_{i} \quad\left(\mu_{i} \in[\beta-1, \beta]\right), \epsilon_{i}$ is the numeric equivalent of the main feature of the elective - its field of study (it is normalized to 1 , so $\left.\in_{i} \in[0,1]\right)$. There is always some basic motivation $\beta$ of a student to go to any course, although it is not that big for the electives that the student denies going to. I'm implying here that the further student is from the elective course in the sense of numeric difference of their study preferences $\pi_{k}$ (the scale is the same as the one of elective's field of study, $\pi \in[0,1])$ with $\in_{i}$, the less probable it is for this student to choose the course.

Differentiation proves this choice heuristic: $\frac{d \mu_{i}}{d \pi}=\pi-\epsilon_{i}-$ if the preferences of a student are the same as the study field of the elective course, then it will be the best choice for this particular student.

\section{How is the Game Going?}

General function, showing the overall state of the game, can be denoted this way: 


$$
\sigma=\left(\frac{\left(\mu_{11}-\mu_{12}\right)-\left(\mu_{21}-\mu_{22}\right)}{\beta}\right)^{2}, \sigma \in[0,1] .
$$

Where the value zero of $\sigma$ means that both students are on the same elective course (meaning it is "overcrowded" and it is impossible to learn) or the preferences of the students are not satisfied (one of the possible causes for such a situation may be that the pool of electives is centred on the discipline students don't necessarily feel interested in). Value one, on the contrary, means that students are on their own elective courses and their preferences are too different ever to choose the same elective course.

However, if the preferences of the students are similar enough or the elective pool is not diverse (i.e. both courses are almost the same), the choice of both students will be the same with a high probability (the game function proves that - it gives zero for the case with $\epsilon_{1}=1, \in_{2}=1, \pi_{1}=0, \pi_{1}=0, \beta=2$ and is close to zero in some less extreme cases). Therefore, having preferences of the students and study fields of the electives as the only criteria for choice is not enough to resolve this coordination problem.

\section{The Controlling Measures}

Here three Bowles-inspired (Bowles, 2006) ways emerge: to control the choice with some external authority, deciding who'll be advantaged in the choice (the "state" solution); to have some agreement to emerge between the students on how they will choose their electives based on the choice of others (the "community" way); to introduce some kind of property rights to elective courses for some students to regulate the choice of others (the "market" way).

Most universities implement the "state" way. Some authority prioritizes some students over the others in their elective course choice and controls the number of students on the electives. However, such systems are not isolated, and students can communicate with each other and have agreements and plans on who'll go where thus the "community" way is partially present in the current elective choice system too.

\section{The "State" Way}

"State" way in the elective course choice system usually involves prioritization of students by measurable criteria - grades (Grade Point Average (GPE) or the grades for a previous semester), year of study, speed of choice. This prioritization is not obviously connected with the study preferences of the students, so it may help to resolve situations when students pick the same elective, or the electives are almost the same. Still, it leaves some students on the courses they don't necessarily like as a tradeoff. Thus, the choice of the elective course in the situation of the "state"-like regulation is governed by this kind of choice function:

$$
\mu_{k i}=\frac{\beta}{\rho_{k}}-\left(\pi_{k}-\epsilon_{i}\right)^{2} .
$$

Where $\rho_{k}$ is the rating position of the student $s_{k} . \rho_{k} \in[1, n], S=\left\{s_{1}, \ldots, s_{n}\right\}$ and the higher the rating position of the student is (and the lower the numeric value of $\rho_{k}$ is), the more possibility there is for the student to be on the elective they want to be on. For our $2 \times 2$ game, the value of $\beta / \rho_{k}$ will be $\beta$ for one of the students and $0.5 \beta$ for the other. Then, the outcome of the game will shift towards the student with the higher grades (if it's the grades that students are ranged by), because they will have a higher motivation ${ }^{1}$ to choose their preferred electives.

The derivative of this choice-function looks like this $\frac{d \mu_{k i}}{d \rho_{k}}=-\frac{\beta}{\rho_{k}^{2}}-2\left(\pi_{k}-\epsilon_{i}\right)$, and, in the extremum point, $\beta / \rho_{k}^{2}=-2\left(\pi_{k}-\epsilon_{i}\right)$, which means that the lower the student is in the rating, the more carefully they need to choose their elective because of their inability to get the course they want will scale exponentially. Although this may seem like nonsense, it makes sense in this model, initially built on the idea of the preferences of the students. And, quite realistically, if there is the same pool of electives, the game turns to a probabilistic one - not knowing what the student on the first rating position will pick, the second student will almost flip the coin and hope not to be moved to the elective they didn't like (either all of them or none of them).

This enhancement solves the problem of the overcrowding, given that the students' interests

\footnotetext{
${ }^{1}$ After the introduction of the external control, calling the choice of an elective course made by a student a "motivation" loses a part of its meaning, but it's not that harmful, so let it
} be there. 
are diverse, and so are the course's topics, diversifying it even more. Of course, additional criteria can always be introduced, but, so far, this is already a satisfactory model of the elective choice system. However, the inability to cope with the probabilistic choice in case of similar (or normallydistributed) courses and students' interests is one of the coordination problems that emerge both in the game described above and in the practice of the universities and that, it seems, cannot be easily solved without the control over the elective capacity.

\section{The "Community" Way}

In the real world, a part of this non-disparity problem gets regulated by the interactions and shared experiences of the students that either help the choice system to distribute students justly, or tear it to pieces as a result of (dis)organized effort. Ignoring such phenomena would be harmful. However, the tools of simple game theory fall short of ways to work with such a group-oriented idea as a rumour, especially in the case of an overly simplified $2 \times 2$ game. I will only show one possible choice-function that takes the opinion of the others into account:

$$
\mu_{k i}=\frac{\beta}{\rho_{k}}-\left(\frac{\pi_{k}-\epsilon_{i}+\left(\sum_{n=1}^{m} \pi_{n}-\epsilon_{i}\right)}{m}\right)^{2},
$$

where $m=a$ number of friends that $k$ has.

With such a model, the person that relies too much on their friends (or just has too much of them) will have no hints on which course to choose if these friends have no information about the courses in question or are too different in their relation to the course. This reliance on someone else's opinion can also be used as an explanation of the interest-based groups' occurrence, but that goes much beyond both this paper and the decribed $2 \times 2$ game.

\section{Agent-based Model}

Based on the ideas of the game-theoretic model from before, an agent-based model was built with the tools provided by the NetLogo agentbased modelling environment. Due to this environment being modelling-ready, a lot more concepts found their way into this model, including happiness, grading system, students' rating, choice, and elective popularity. This list mirrors the one, based on the Artino \& Stephens 2007 study and Sabot \& Wakermann-Linn 1991 paper, proposed before: "motivation, elective difficulty, [and] major preference" (Bologov, 2020, p. 5) of a student are expressed through the happiness and choice, while the "grade history and the opinion of peers" (Bologov, 2020, p. 5) are collaterally used in the "state"-regulatory grading, rating, and elective selection system.

\section{Happiness}

The main new concept that was not present in the game-theoretic model is happiness. Although happiness is quite a vague term, it is general enough to represent the psychological well-being, risk, and confidence of a person. Using this meaning of happiness, we can make it responsible for the confidence, risky behaviour and the motivation of a student to study.

As an example, here's the new choice-function that is now much more dependent on the happiness of students:

$$
\mu_{k i}=\left(\pi_{k}-\epsilon_{i}\right)^{2}+\left(\operatorname{random}\left(\chi_{\max }-\chi_{k}\right)\right),
$$

where $\chi$ is student's happiness level. It accords with the Prospect Theory idea of different behaviours while in losing state and while in winning state - while losing, a person risks more and tries to win in any way possible. In contrast, the winning person tries to preserve the prize. This risky oscillating change of mood governs how student studies, chooses elective courses and will the student stay in the institution or leave it because of exhaustion.

\section{Elective Change}

The idea that electives need to change and do actually change was foreign to the game-theoretic model due to its limitations. Still, the agent-oriented model allows for the choice between different models of how electives change. There are two models for elective selection: based on student's interest and, consequently, the number of students on elective, and the random selection.

When there's the selection based on the elective popularity, only the electives with the maximum number of students remain. It might have lead to the stagnation and some stable equilibrium 

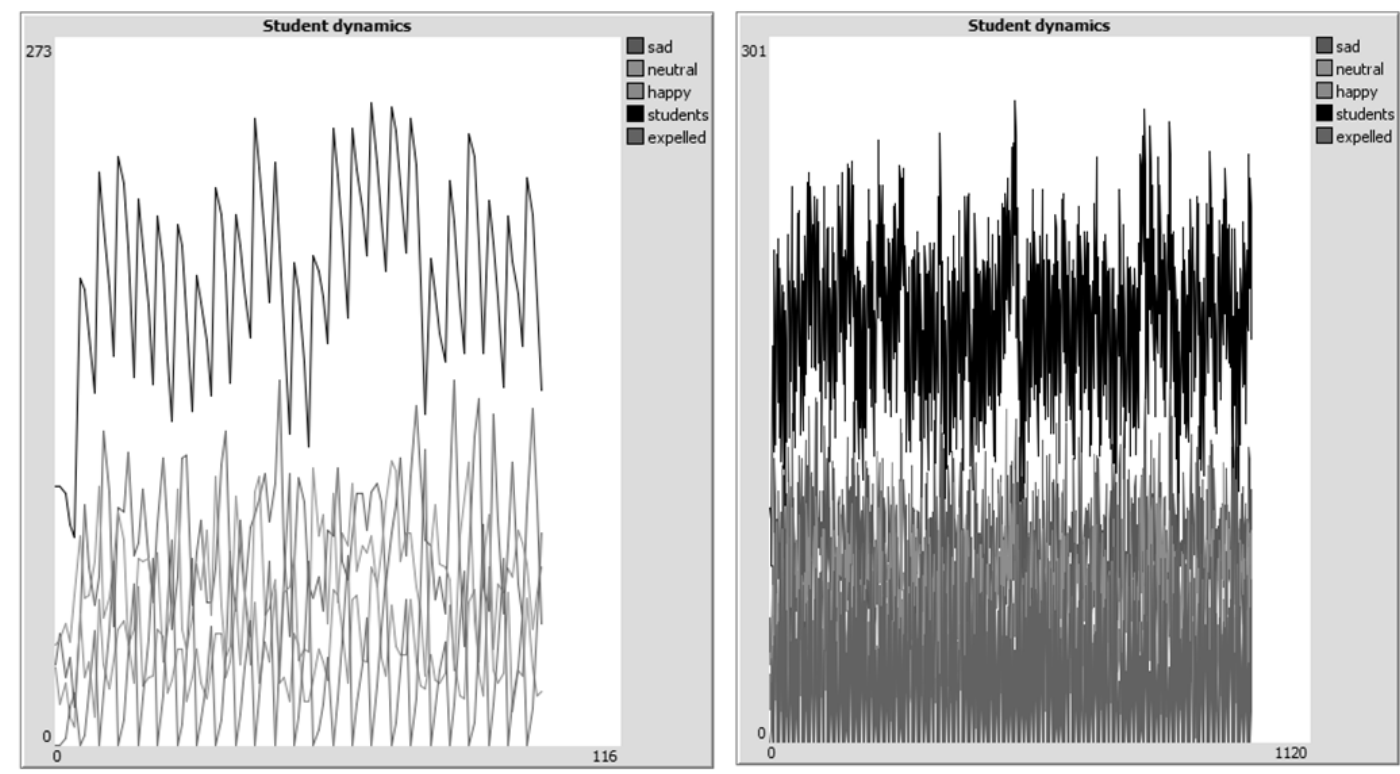

Fig. 1. Seven-median system mid-term \& long term oscillations

Source: The author.

if the interests of the students were not uniformly distributed. But in the situation of uniform students' interest distribution and the competition for interests, there's no stable equilibrium both due to the students' chaotic behaviour and electives' complementarity.

The random elective selection changes several random electives with others. While this may seem as the chaos-provoking selection, it appears to provoke as much or even less chaos than the students' number-based selection, probably because the student-maximum course selection reinforces the anomalies of the distribution that centre around some particular elective and stay there.

\section{Student Elective Choice Privileges}

Because the "state" way of regulating elective selection usually uses some criteria to compare students by, there is an inevitable rating system that emerges out of it. Several systems are modelled: the GPA rating, the module-based rating, and a random rating.

The GPA-based rating is looking at all the grades the person had during their study time and compared the average grade with others to make a rating of students. Because the GPA of one grade equals to this grade, and the more there are grades, the closer they are to the normal distribution. The freshmen that come every year in this system will have both advantage and disadvantage - if they are lucky, they can easily get above the second-, third-, or fourthyear students. Still, if they are unlucky, they will be at the bottom of the rating and their GPA will consequently get lower which can then reinforce the divergence because of the inability to choose the elective that is close to preferences of the one.

The module-based rating does the same as GPA-based one, but takes a smaller period, thus shrinking the differences between the students of different years and making them relatively equal. No wonder that so many institutions use the module-based rating systems - they are both more comfortable to use and are relatively just to the students.

The random system is, then, going even closer to equality of the students, because it puts students in the rating in the random order every time. However, this system is the most unjust of students. It causes the biggest oscillations in the number of students over time because of unpredictable expulsions happening because of the... randomness of the distribution.

\section{The Grading Systems}

There are a lot of grading systems, but I think that having four of them is a good survey of the main ideas in grading. These four systems are uniform grading, seven-median grading rule, effort-based grading, and random grading.

The seven-median system is the one that my school uses, and one of the goals of this paper 


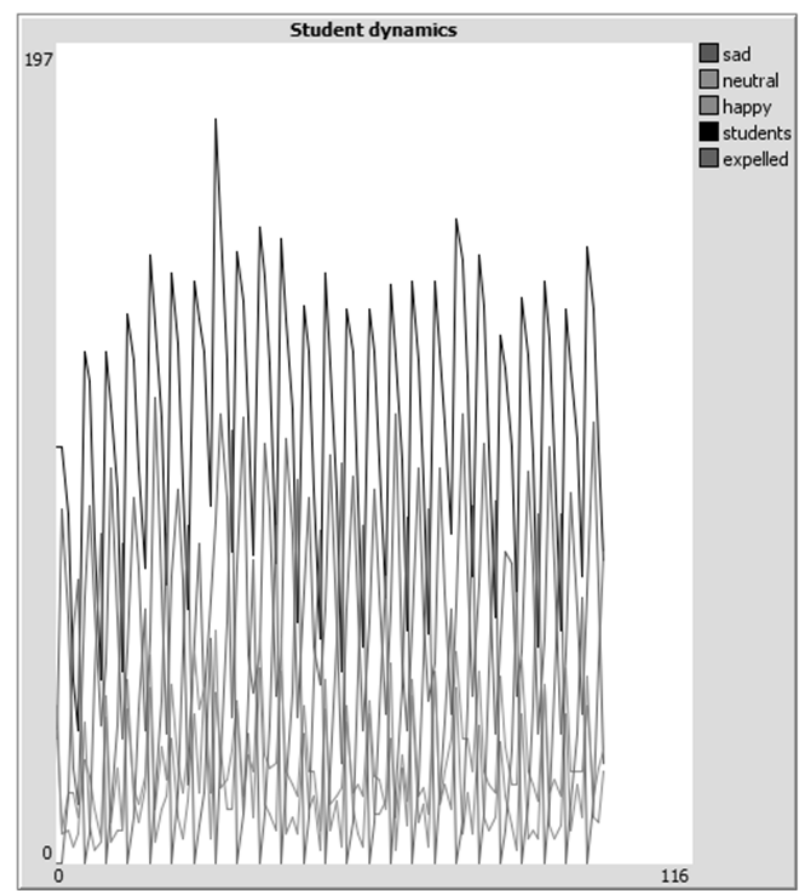

Fig. 2. Uniform grading system mid-term behaviour

Source: The author.

was to look at how well this system can make students' choice of electives satisfied and if this system is the optimal one in terms of "state"-like control of elective choice. The essence of the seven-median is the idea that among the grades for any course, there should be the same number of grades below seven as above seven. This system sounds like the one that is controlling both students and instructors from the possible chaos. I can say it does, because, after some initial risky oscillations, it becomes stable enough for quite a long time. Although after 800 modules (200 years) it started to show some unpredictable peaks and widen the amplitude of oscillation, it seems stable enough.

Uniform system (i.e. the one where all the students, sorted in the order of their efforts, are given the grades from 0 to 10 ) was constantly underestimating the efforts of students. It caused all the students to leave the school out of exhaustion eventually. However, the reason for that was that the average effort of students, set by myself, that students have put to work was higher than the average grade (seven versus five). After setting the average effort to five, the uniform distribution has worked even more stable as seven-median, because it turned into an approximate five-median. However, then, uniform distribution needs to be changed into a non-uniform one to suit some real situations

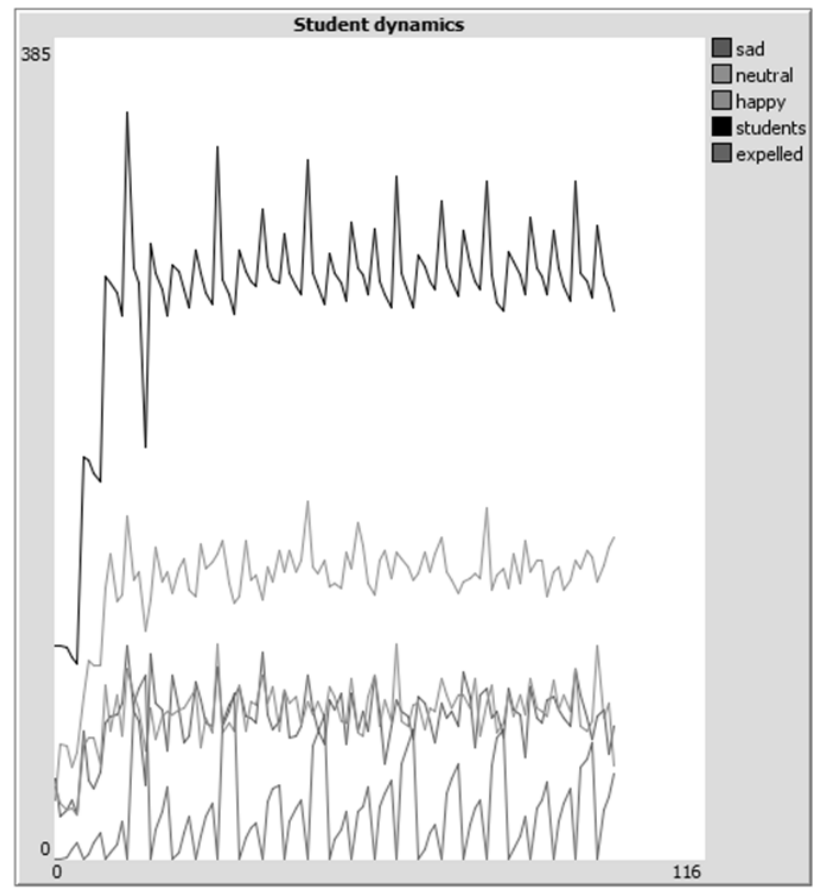

Fig. 3. Effort-based grading system mid-term behaviour Source: The author.

and to be stable enough, which is too much of a sacrifice.

Effort-based system (i.e. the one that was just measuring the efforts of students with some constant error) has been satisfying most students' need for the acknowledgement of their efforts but made them get stuck on the neutral mood, therefore making up for less motivation and the essential chaos that can generate new useful events. But even a little of chaos in the evaluation of efforts were causing unexpectedly strong oscillations. However, this system was the most stable out of all the grading systems in the long term, given the stable effort and a small grading error.

The random grading system was making the same mistake of students' efforts underestimation as a uniform grading system with high efforts. Yet, it was more stable because of randomness - some students randomly graded highly, were satisfied by the grades and stayed in the school. However, this system, especially together with other random systems, was creating the strongest oscillation that this model was able to create - up to almost all the students leaving the school and then regaining the numbers to nearly twice the initial state.

\section{Lessons to Learn}

This study is not nearly a complete one. There are a lot of ways to go: the models can be made 
more realistic by adding the professors as a group of agents, by making the supposed difficulty of the course to influence the choice; the perspectives of the Bowles-inspired "community" and "market" solutions are yet to be explored, for example, by bringing the interactions proposed in the game-theoretic part of the paper, into the agent-based model where the interactions will fit better.

The current results are useful already. Although the seven-median module-rating system may seem like an unfavourable choice after the comparison given above, I understand now why the specific kind of seven-median grading was so ubiquitous in my school - the changes in it made the grading shift towards the effortbased one, causing both disperse and stable elective-choice and studying system and giving a solid ground for future courses. Then, the changes that the seven-median module-rating system needs only a minor change in comparison to what I supposed at the beginning of this work.

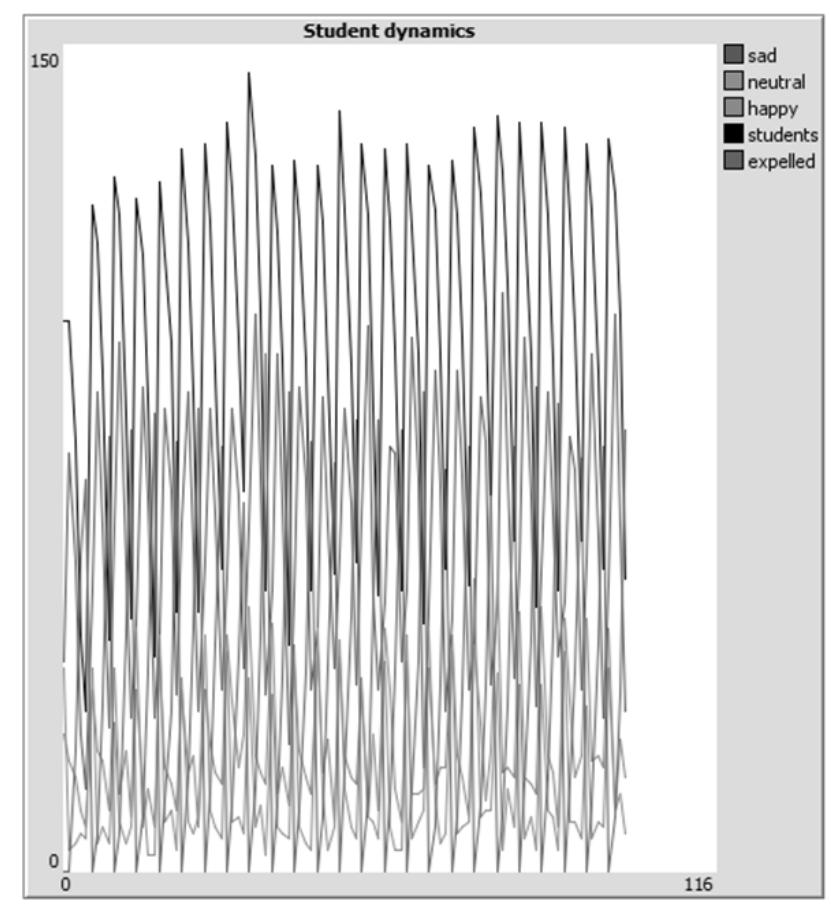

Fig. 4. Random grading system together with the random rating system and random elective selection: mid-term behaviour

Source: The author.

\section{References}

Artino, A., Stephens, J. (2007). Motivation and Self-Regulation in Online Courses: A Comparative Analysis of Undergraduate and Graduate Students.

Bologov A. (2020). Literature Review for Economics: Brain, Behaviour, Institutions.

Bologov A. (2020). The screenshots of the plot made in the NetLogo agent-based modelling environment. Created on April 6 $6^{\text {th }}, 2020$.

Bowles, S. (2006). Microeconomics: Behavior, Institutions, and Evolution. Princeton, New Jersey: Princeton University Press.

Sabot, R., Wakeman-Linn, J. (1991). Grade Inflation and Course Choice. Journal of Economic Perspectives, 5(1), 159170. DOI: $10.1257 /$ jep.5.1.159.

Оценка возможности системы факультативного выбора

Артем Бологов

Аннотация. Я учусь в гринфилдской школе свободных искусств, а это значит, что в процессе обучения происходит много экспериментов и внезапных исправлений. В то время как некоторые вещи меняются, одна вещь прошла через три года существования школы почти без изменений - система факультативного выбора учебных курсов. И теперь, когда эта система поставлена под сомнение относительно того, способствует ли она развитию личного интереса студентов к конструктивному и обоснованному распределению факультативных занятий, я хочу оценить способность нынешней системы факультативного выбора семестровой рейтинговой системы с семимедианной оценкой распределения студентов и выяснить, является ли эта система стабильной в критических условиях. Я предполагаю, что эта система будет достаточно стабильной в краткосрочной перспективе, но через некоторое время ее нужно будет изменить. Ключевые слова: модели; основанные на теории игр; агентные модели; система элективного выбора 